\title{
Morphometric studies on the embryonic gall bladder and cystic duct of Gaddi Sheep in different prenatal age groups
}

\author{
Raheeqa Razvi* and Rajesh Rajput \\ Department of Veterinary Anatomy, Dr. G.C.Negi College of veterinary and Animal Science, CSK.HP.KV- \\ Palampur (H.P), INDIA \\ *Corresponding author. E-.mail:doctorrahika356@gmail.com \\ Received: November 8, 2016; Revised received: July 18, 2017; Accepted: February 17, 2018
}

\begin{abstract}
The objective in the present study was to reconnoiter the morphological structure and biometrical parameters of embryonic gallbladder and cystic duct during the fetal life of Gaddi sheep. A Total number of 40 Gaddi sheep foetii samples were collected irrespective of sex and without any external anomaly or pathology. The age estimation of each foetus was done and accordingly the foetii were grouped as; group-I (1-60days), group-II (61-90days) groupIII (91-120days) and group-IV (121 -full term). The gall bladder from each foetii were excised hygienically. Gall bladder appeared at Crown Rump Length CRL $6.0 \mathrm{~cm}$ (46 days of gestationl age) and was slate blue colour in fresh state and settled into the visceral surface of right lobe of liver. It had single opening which continued as cystic duct. The maximum length and width of gall bladder $(1.85 \mathrm{~cm}$ and $0.75 \mathrm{~cm}$ respectively) and cystic duct $(1.68 \mathrm{~cm}$ and $0.18 \mathrm{~cm}$ respectively) increased with the advancement of gestational age.
\end{abstract}

Keywords: Gall bladder, Gaddi sheep, Micrometric

\section{INTRODUCTION}

The gall bladder is a storage reservoir that allows bile acids to be delivered in a high concentration and in controlled manner to the duodenum for solubilization of dietary lipid (Shaffer, 2000). It forms a part of the biliary system. Other structures included in the biliary system are the liver and bile ducts. The biliary system consists of the organs and ducts that produce, transport, store and secrete bile into the duodenum (Sharma, 2004). The gall bladder usually lies recessed into the undersurface of the right lobe of the liver (Standring, 2008). Gartner and Hiatt (2009) reported that the gall bladder resembled a sack with a single opening and this opening continuous with the cystic duct.

Having the knowledge of development of gallbladder is considerably important; because abnormal types of gallbladder may be associated with congenital malformations or anomalies. Anomalies and congenital pathologies of gallbladder which can be diagnosed in fetuses include floating, left sided, septated or bilobed gallbladder, as well as agenesis of gallbladder (Bronshtein et al., 1993). It has been reported that a detailed description of morphometric structures related to localization and type of gall bladder may be useful in diagnostic procedures such as ultrasonographic examination, and treatment (Callen, 1997). Besides, having the knowledge of normal development of gallblad- der is important in describing the conditions such as agenesis of extrahepatic biliary ducts, variations of gallbladder and its ducts (Goldstein et al., 1994). Congenital absence of gallbladder and its relationship with some other congenital anomalies, and content of gallbladder (sludge, stone, etc.) are important to examine in neonates.

In goats, sheep, dogs and cats, the extra hepatic biliary ductal system seemed to arise from the gall bladder as the cystic duct, with which the individual hepatic / lobar ducts joined to form the common bile duct. While the gall bladder and the cystic duct are completely lacking in horse. The absence of gall bladder was also observed in marsh dear (Borges et al., 2002).

The main objective of the present study was to obtain the normative morphometric data of gall bladder and cystic duct throughout the gestational age. Only after obtaining the normative data one can compare it with deviations or morphometric abnormalities if found during gestational age and is also useful to compare it with data of post-natal period. The data of this study can be used as base line data whenever further research will be carried out in same area of research.

\section{MATERIALS AND METHODS}

All procedures were conducted in accordance with guide lines for animal experimentation of the Faculty of Veterinary Science, Department of Veterinary Anatomy, Dr.G.C.Negi, College of Veterinary and Animal 
Science, CSK.HP.KV., Palampur, Himachal Pradesh (India).

Sample collection and age estimation: Gravid uteri of Gaddi sheep were collected from and around local slaughter houses of Palampur region of Himachal Pradesh. Uteri then immediately opened to obtain fetus, which were washed properly and age of fetus was calculated. CRL (crown rump length) of foetii were recorded for age estimation by using the following given (Hejazi et al., 2011):

$\mathrm{Y}=2.74 \mathrm{X}+30.15$

Where, $Y=$ age of fetus in day, $X=$ Crown Rump Length in $\mathrm{cm}$

The foetii were grouped as; Group-I (1-60 days), Group-II (61-90 days) Group-III (91-120 days) and Group-IV (121 -full term). Each group contained ten samples. Liver was than excised from the body of each foetii to expose the gall bladder. The gall bladder so exposed was detached from liver along with its duct (cystic duct).

Morphometric studies of foetal gall bladder: This included the morphological and biometrical observation in different age groups of Gaddi sheep foetii (All these gross parameters were measured by using Vernier caliper)

Morphological observations: This included the observation of gross morphology (location, shape and color) of gall bladder its duct system.

Biometrical observations: It included the measurement of following parameters:

Length of gall bladder: it included the distance between transverse planes passing through the upper and lowermost points of the gall bladder.

Width of gall bladder: Distance between parallel vertical planes touching the extreme margins of the gall bladder.

Length of cystic duct: Distance from the origin of cystic duct at the top of neck of gall bladder to its union with common hepatic duct for formation of common bile duct.

Width of cystic duct: Diameter of cystic duct at its widest margins.

Statistical analysis: The data of embryonic gall bladder so obtained were analyzed by using Univariate ANOVA at 5\% level of significance. Multiple comparison tests were used to compare the difference between the groups. All analysis was done by using SPSS-17. Statistical calculations (mean \pm standard error) were recorded according to the standard statistical procedures recommended by Snedecor and Cochran (1994).

\section{RESULTS AND DISCUSSION}

The results of our study provide normative data for growth of the fetal gall bladder throughout gestation and demonstrate that the growth of the organ is linear across gestation. No literature as such was available on the embryonic gall bladder in different animals and

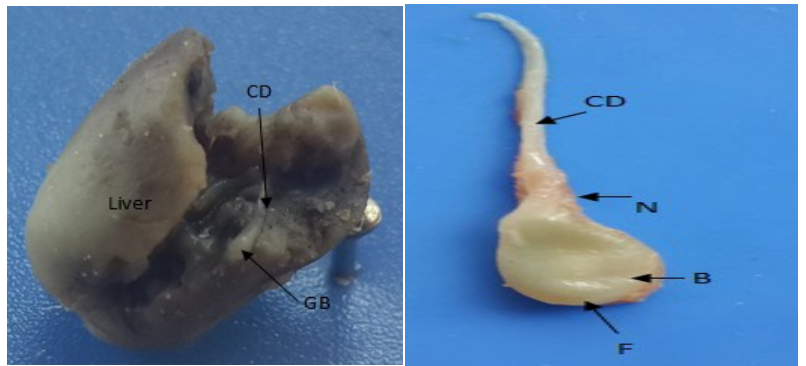

Fig. 1. Photograph showing Fig. 2. Photograph showing liver with gall bladder $(G B)$ neck $(N)$, body $(B)$ and funand cystic duct (CD) at CRL dus (F) of gall bladder along $6.0 \mathrm{~cm}$ (46 days of gestation). with its cystic duct (CD).

very limited data was accessible with respect to adult gall bladder. So for the discussion purpose the result of present study was compared with the adult gall bladder of different animals.

\section{Gross morphological observations}

Morphology of prenatal gall bladder: The gall bladder was of slate blue colour in fresh state and recessed into the visceral surface of the right lobe of liver. It appeared at CRL $6.0 \mathrm{~cm}$ (46 days of gestation) and resembled like a sac with a single opening and this opening was continuous the cystic duct (Fig. 1). The cystic duct continued with the common hepatic duct and proceeded ahead as the common bile duct which finally opened into the duodenum. Gall bladder consisted of three parts viz: fundus, body and neck (Fig. 2). The fundus was expanded bottom of gall bladder. Near full term the portion of fundus of gall bladder protruded out from inferior border of liver and was visible from parietal surface of liver. The body was dilated portion lying between the neck and fundus. The neck of the gall bladder tapered into the cystic duct.

\section{Biometrical observations}

Length of gall bladder: Its length increased significantly from group-1 to group-IV (Table 1). In group-I, the minimum $(0.41 \mathrm{~cm})$ value for the length of gall bladder was recorded at CRL $6.0 \mathrm{~cm}$ (46 days of gestation) and maximum $(0.52 \mathrm{~cm})$ at CRL $11.0 \mathrm{~cm}(60$ days of gestation). While in group-II, the highest $(0.90$ $\mathrm{cm})$ and lowest $(0.65 \mathrm{~cm})$ values were observed at CRL $14.8 \mathrm{~cm}$ (70 days of gestation) and CRL $22.0 \mathrm{~cm}$ (90 days of gestation) respectively. For group-III, its minimum $(1.00 \mathrm{~cm})$ and maximum $(1.38 \mathrm{~cm})$ values were recorded at CRL $24.5 \mathrm{~cm}$ (97 days of gestation) and at CRL $32.0 \mathrm{~cm}$ (117 days of gestation) respectively. In group-IV, the highest $(1.30 \mathrm{~cm})$ value for the length gall bladder was recorded at CRL $33.5 \mathrm{~cm}$ (121 days of gestation) and lowest $(1.85 \mathrm{~cm})$ at CRL 42.5 $\mathrm{cm}$ (146 days of gestation).

Width of gall bladder: The width of gall bladder increased significantly from group-I to group-IV (Table 1). Its overall width ranged from $0.10 \mathrm{~cm}$ to $0.75 \mathrm{~cm}$. For group-I, its minimum $(0.10 \mathrm{~cm})$ width was recorded at CRL $6.0 \mathrm{~cm}$ (46 days of gestation) and maximum $(0.18 \mathrm{~cm})$ at CRL $9.8 \mathrm{~cm}$ (57 days of gestation). While 
Table 1. Biometrical parameters (Mean \pm S.E) of gall bladder in different age groups of prenatal Gaddi sheep.

\begin{tabular}{lllll}
\hline Parameters (cm) & $\begin{array}{l}\text { Group-I } \\
(\mathbf{1 - 6 0} \text { days) }\end{array}$ & $\begin{array}{l}\text { Group-II } \\
\mathbf{( 6 1 - 9 0} \text { days })\end{array}$ & $\begin{array}{l}\text { Group-III } \\
\mathbf{( 9 1 - 1 2 0} \text { days })\end{array}$ & $\begin{array}{l}\text { Group-IV } \\
(\mathbf{1 2 0}-\text { full term) }\end{array}$ \\
\hline Length of gall bladder & $0.55^{\mathrm{a}} \pm 0.25$ & $0.98^{\mathrm{b}} \pm 0.53$ & $1.49^{\mathrm{c}} \pm 0.39$ & $1.87^{\mathrm{d}} \pm 0.61$ \\
& $(0.41-0.52)$ & $(0.65-0.90)$ & $(1.00-1.38)$ & $(1.30-1.85)$ \\
Width of gall bladder & $0.20^{\mathrm{a}} \pm 0.09$ & $0.38^{\mathrm{b}} \pm 0.28$ & $0.61^{\mathrm{c}} \pm 0.22$ & $0.79^{\mathrm{d}} \pm 0.38$ \\
& $(0.10-0.18)$ & $(0.15-0.38)$ & $(0.40-0.58)$ & $(0.55-0.75)$ \\
Length of cystic duct & $0.71^{\mathrm{a}} \pm 0.47$ & $1.07^{\mathrm{b}} \pm 0.51$ & $1.38^{\mathrm{c}} \pm 0.68$ & $1.64^{\mathrm{d}} \pm 0.63$ \\
& $(0.50-0.70)$ & $(0.98-1.00)$ & $(1.09-1.38)$ & $(1.20-1.68)$ \\
Width of cystic duct & $0.10^{\mathrm{a}} \pm 0.09$ & $0.14^{\mathrm{b}} \pm 0.58$ & $0.21^{\mathrm{c}} \pm 0.95$ & $0.24^{\mathrm{d}} \pm 0.11$ \\
& $(0.03-0.05)$ & $(0.05-0.10)$ & $(0.09-0.18)$ & $(0.10-0.18)$ \\
\hline
\end{tabular}

Values having different superscripts in each row differ significantly $(\mathrm{P}<0.05)$; Values within parenthesis denote the range of parameter.

in group-II its largest $(0.15 \mathrm{~cm})$ and smallest $(0.38 \mathrm{~cm})$ values were recorded at CRL $14.8 \mathrm{~cm}$ (70 days of gestation) and maximum at CRL 21.4 (88 days of gestation). In group-III the smallest $(0.40 \mathrm{~cm})$ and largest $(0.58 \mathrm{~cm})$ values were observed at CRL $24.5 \mathrm{~cm}(97$ days of gestation) and at CRL $31.3 \mathrm{~cm}$ (115 days of gestation) respectively. The minimum $(0.55 \mathrm{~cm})$ and maximum $(0.75 \mathrm{~cm})$ values for the width of gall bladder were recorded at CRL $33.5 \mathrm{~cm}$ (121 days of gestation) and at CRL $42.5 \mathrm{~cm}$ (146 days of gestation).

The length and width of gall bladder increased significantly with the advancement of gestational age. Khalil et al. (2004) reported that the average length of gall bladder was $5.7 \mathrm{~cm}$ in adult sheep and goat and its average width as $2.4 \mathrm{~cm}$ and $2.3 \mathrm{~cm}$ in adult sheep and goats respectively. He further reported the average width of gall bladder was $4.7 \mathrm{~cm}, 2.7 \mathrm{~cm}$ and $1.3 \mathrm{~cm}$ and its average length as $11.3 \mathrm{~cm}, 5.6 \mathrm{~cm}$ and $5.6 \mathrm{~cm}$ in adult oxen, dogs and cats respectively. Cortez and Maala (2010) recorded the length and width of gall bladder as $15.8 \mathrm{~cm}$ and $7.6 \mathrm{~cm}$ in adult Philippine water buffalo.

Length of cystic duct: Its length increased significantly from group-1 to group-IV (Table 1). In group-I, the minimum $(0.50 \mathrm{~cm})$ value for the length of cystic duct was recorded at CRL $6.0 \mathrm{~cm}$ (46 days of gestation) and maximum $(0.70 \mathrm{~cm})$ at CRL $11.0 \mathrm{~cm}$ (60 days of gestation). While in group-II, the highest $(0.98 \mathrm{~cm})$ and lowest $(1.00 \mathrm{~cm})$ values were observed at CRL 14.8 $\mathrm{cm}$ (70 days of gestation) and CRL $22.0 \mathrm{~cm}$ (90 days of gestation) respectively. For group-III, its minimum $(1.09 \mathrm{~cm})$ and maximum $(1.38 \mathrm{~cm})$ values were recorded at CRL $24.5 \mathrm{~cm}$ (97 days of gestation) and at CRL $32.0 \mathrm{~cm}$ (117 days of gestation) respectively. In group$\mathrm{IV}$, the highest $(1.20 \mathrm{~cm})$ value for the length of cystic duct was recorded at CRL $33.5 \mathrm{~cm}$ (121 days of gestation) and lowest $(1.68 \mathrm{~cm})$ at CRL $42.5 \mathrm{~cm}$ (146 days of gestation).

Width of cystic duct: The width of cystic increased significantly from group-I to group-IV (Table 1). Its overall width ranged from $0.03 \mathrm{~cm}$ to $0.18 \mathrm{~cm}$. For group-I, its minimum $(0.03 \mathrm{~cm})$ width was recorded at CRL $6.0 \mathrm{~cm}$ (46 days of gestation) and maximum $(0.05 \mathrm{~cm})$ at CRL $9.8 \mathrm{~cm}$ (57 days of gestation). While in group-II its largest $(0.05 \mathrm{~cm})$ and smallest $(0.10 \mathrm{~cm})$ values were recorded at CRL $14.8 \mathrm{~cm}$ (70 days of gestation) and maximum at CRL 21.4 (88 days of gestation). In group-III the smallest $(0.09 \mathrm{~cm})$ and largest $(0.18 \mathrm{~cm})$ values were observed at CRL $24.5 \mathrm{~cm}$ (97 days of gestation) and at CRL $31.3 \mathrm{~cm}$ (115 days of gestation) respectively. In group-IV, the minimum $(0.10 \mathrm{~cm})$ and maximum $(0.18 \mathrm{~cm})$ values for the width of cystic duct were recorded at CRL $33.5 \mathrm{~cm}$ (121 days of gestation) and at CRL $42.5 \mathrm{~cm}$ (146 days of gestation) respectively.

The length and with of cystic duct also showed a significant increased with advancement of embryonic age. Khalil et al., (2004) reported the average length of cystic duct as $3.3 \mathrm{~cm}, 3.1 \mathrm{~cm}, 3.5 \mathrm{~cm}, 3.2 \mathrm{~cm}$ and 1.2 $\mathrm{cm}$ in adult sheep, goat, oxen, dogs and cats respectively and the average width of cystic duct as $2.7 \mathrm{~cm}$, $3.7 \mathrm{~cm}, 11.0 \mathrm{~cm}, 5.7 \mathrm{~cm}$ and $5.7 \mathrm{~cm}$ in adult sheep, goat, oxen, dogs and cats respectively.

\section{Conclusion}

The given results provide normative data of the fetal gall bladder of Gaddi sheep in various dimensions and across gestational ages (Table 1), which can be used to assess variations from the norm. In addition, these data offer the potential for prenatal diagnosis of additional extrahepatic lesions. There were changes in the gross and histomorphology of the thickness of the gallbladder wall in relation to age in this study. To establish a standard data, similar study with larger sample size in different age groups and using more advance methods including both sexes are recommended.

\section{ACKNOWLEDGEMENTS}

The Department of Science and Technology, New Delhi, India is acknowledged for providing the financial support in the form of DST/ INSPIRE Fellowship (2013/481) to Ms. Raheeqa Razvi.

\section{REFERENCES}

Borges, M. E., Machado, M.R.F., Oliveira, D., De-Souza, M.W. and Duarte, J.M.B. (2002). Morphological as- 
pects of the liver of marsh deer (Blastocerus dichotomus). Barazilian J. Vet. Res. and Ani. Sci., 39(2):78-80

Bronshtein, M., Weiner, Z., Abramovici, H., Filmar, S., Erlik, Y. and Blumenfeld, Z. (1993). Prenatal diagnosis of gall bladder anomalies - report of 17 cases. Prenat. Diag. 13(9):851-861.

Callen, P.W. (1997). Ultrasonography in obstetrics and gynecology (translation). In: Guner $\mathrm{H}$ (trans ed) 3rd edition. W. B. Saunders, Philadelphia, pp 818-833.

Gartner, L.P. and Hiatt, J.L. (2009). Color textbook of histology. 3rd edition. India (Elsevier) 3: 434-36.

Goldstein, I., Tamir, A., Weisman, A., Jakobi, P. and Copel, J.A. (1994). Growth of the fetal gall bladder in normal pregnancies. Ultrasound Obstet. Gynecol. 4(4):289293.

Hejazi, S., Eilyad, I. and Moahmmad, T. (2011). Study of Testis Development in Sheep Fetus. Adv. in Environ. Bio. 5(9): 2750-2755.
Shaffer, E. A.(2000). Control of gall bladder motor function. Alimentary Pharma. and Therap. 14(2): 2-8.

Sharma, S. (2004). Development of Biliary Tract. Encyclopedia of Gastroentrology: Emb. Uni. Hosp., USA. p. 210-11.

Snedecor, C.W and Cochran, W.G. (1994). Statistical methods. $9^{\text {th }}$ edn. Iowa state University press, Ames, Iowa.

Standring, S., (2008). Gray's Anatomy. The anatomical basis of clinical practice. In: Borley NR, Healy JC. Abdomen and Pelvis 40. Spain (Churchil Livingstone Elsevier), p. 1177.

Khalil, M.M., Islam, M.N., Khalil, M.M., Khna, M.Z.I. and Hossain, M.I. (2004). Morphology and morphometry of gall bladder, cystic duct and common hepatic duct in man and domestic animals. The Bangladesh Veterinarian 21(2): 101-108

Cortez, E.S. and Maala, C.P. (2010). Anatomy of the gallbladder of the phillippine water buffalo. Philippine Journal of Veterinary Medicine 47(2): 58-65 